\title{
The Effects of Smart Tolling for the Improvement of Traffic Flow on the Seoul Tollgate with ARENA
}

\author{
Seung-Min Noh, Ho-Seok Kang, Seong-Yong Jang ${ }^{*}$ \\ Seoul National University of Science and Technology, Seoul, Korea \\ *syjangeseoultech.ac. kr
}

Received: April 2, 2019; Accepted: October 15, 2019; Published: September 10, 2020

\begin{abstract}
The effects of traffic flow improvements were compared in terms of real traffic data by using the level of congestion, throughput, and average duration time criteria. A current situation and a situation with smart tolling were considered in order to ensure the reliability of the results. The simulation consisted of eight scenarios, the error rates were checked with 30 replications, and the error rates were noted to be lower than $0.5 \%$. The scenarios were categorized by vehicle speeds that could affect subsequent vehicles. The smart tolling model was better than the current model overall. In particular, the results of comparing lifelike scenario 1 and scenario 8 with smart tolling are key. The results showed that the level of congestion and average duration time could be decreased to approximately $46 \%$. With regard to the results, there are significant impacts on improving traffic flow while maintaining five lanes, unlike in the current model.
\end{abstract}

Keywords: Smart Tolling, Simulation, Traffic Flow, ARENA, AET

\section{Introduction}

According to a report released by the Ministry of Land, Infrastructure and Transport in January 2019, the number of vehicles registered in Korea was 23.2 million as of December 2018, which denotes an increase of $3 \%$ from 22.52 million in 2017. This means there is 1 vehicle per 2.234 people [1]. As traffic grows, highway traffic is also growing. Traffic is the main cause of highway congestion. Tollgates can also be a major cause because vehicles need to stop at these gates unless they have a Hi-pass. In addition, there are various causes such as excessive lane changes and traffic accidents.

The Korea Expressway Corporation installed Hi-pass lanes on the highways in 2007, starting with a pilot project in 2000 to ease the congestion of highways and tollgates. Since then, the 


\section{Journal of Advanced Simulation in Science and Engineering}

number of Hi-pass users has continued to increase, and $80 \%$ of daily highway traffic used a Hipass as of early July 2017 [2]. Despite this high utilization rate, users complained because the Hi-pass vehicles had to drive at speeds of $30 \mathrm{~km} / \mathrm{h}$ or less [3]. The Hi-pass lanes and regular lanes are still operated together at tollgates in Korea. This is causing conflicts and excessive lane changes owing to differences in speed between different lanes, which can lead to serious safety problems. This also contributes to traffic congestion on the roads. In Korea, it is difficult to install Hi-pass for all tollgates. Thus, a realistic alternative is needed to prevent heavy traffic congestion caused by conflict between Hi-pass lanes and regular lanes. Lately, developments in information and communication technologies have led to changes in intelligent transportation systems and discussions on smart tolling systems to remedy the shortcomings of Hi-pass. According to a report released by the Ministry of Land, Infrastructure and Transport in January 2017 , the smart tolling system was introduced as an unmanned automatic payment system using existing Hi-pass or video recognition technology [4].

In this study, first, explored the characteristics of overseas AET. the subjects were limited to vehicles entering Seoul from the large tollgate, which was frequently congested.

According to the Korean National Police Agency's notice, the speed limit of the section from Cheonan IC to Yangjae IC, which includes Seoul Tollgate, is $110 \mathrm{~km} / \mathrm{h}$, different from the speed limit of $100 \mathrm{~km} / \mathrm{h}$ for the rest of the section [5]. Consequently simulation was performed assuming various speeds.

The effects of assuming a smart tolling system to be applied nationwide in 2020 along with maintaining existing driving speeds in multilanes will be compared.

\section{Theory Background}

Recently, a study on the operation of tollgates on highways was conducted by examining traffic congestion and safety owing to relative speeds and conflicts between Hi-pass lanes and regular lanes. Research on smart tolling is also underway.

Variables such as Hi-pass traffic, the lengths of fields and roads for entering and exiting, and adjustments of Hi-pass lanes affect the traffic dispersion rate. When placing a Hi-Pass lane, the position is analyzed as a key variable. Hence, selecting a location is the most important factor for balanced distribution in a Hi-pass lane [6]. A simulation model was developed to explore the best integrated operation methods when combining the existing TCS(Toll Collection System) and ETC(Electronic Toll Collection) systems. In addition, the optimum number of Hipass lanes was calculated to reduce vehicle waiting time.

According to the results of a cost benefit analysis, for operators, expanding the number of Hi-pass lanes will increase benefits. For users, an appropriate number of lanes is required owing to increasing costs or latency. If the number of lanes is under-estimated or overestimated, then costs will outweigh the benefits [7]. To improve safety for central Hi-pass lanes, the deceleration time of vehicles owing to relative speed and conflicts were analyzed. The proposed 


\section{Journal of Advanced Simulation in Science and Engineering}

methods of operation were the connection between the central Hi-pass and main lanes, prevention of conflicts, secure driving lanes, and stepwise entry [8].

A case study using a micro traffic simulation provided a method for determining the position of Hi-pass lanes considering mobility, stability, and convenience of operation. the result was more efficient when the Hi-pass lanes were located on the left side and were closer to each other [9]. The Hi-pass system, which automatically paid during nonstop driving, was expected to ease traffic delays or congestion near tollgates. However, if many vehicles are using the tollgate, it is difficult to avoid delays and congestion, and there is a risk of accidents owing to the conflicts of Hi-pass and regular-lane vehicles.

The study introduced a smart tolling system that has multilanes in nonstop traffic [3]. If smart tolling is installed at the locations of tollgates, the effects on the initial construction expenses and reduced costs are significant. As a result, the smart tolling will help reduce transit time and travel costs [10].

\section{Case Study of AET}

Similar to Smart Tolling, it is being operated under the name of AET abroad. All electronic tolling is a safe and efficient way to collect tolls by enabling drivers to pay without slowing down on highways. AET saves time and reduces fuel costs, improves safety [11]. According to Pennsylvania Trun-Pike's research, the delay and exhaust gas will reducing when the AET system is applied to 4 ICs [12].

Table 1 shows the beginning of introduction and utilization of AET in 5 countries.

Table 1 : Beginning of introduction and utilization of AET in 5 countries (Source: Yeon, B.M 2017)

\begin{tabular}{lll}
\hline Country & Beginning of introduction(year) & Utilization(\%) \\
\hline USA(Florida, Massachusetts) & 2011,2016 & 67,86 \\
Australia & 2013 & 83 \\
Norway & 2007 & 90 \\
Canada & 1999 & 84 \\
Taiwan & 2013 & 94 \\
\hline
\end{tabular}

\subsection{United States of America}

The number of AETs has increased from 6 in 2010 to 22 in 2015. There are various systems by state such as EzPass, SunPass, Fastrak and I-Pass to collect tolls and are currently discussing to enable inter-system compatibility. The Integration and linkage to the collection of intercity tolls will have to be considered to maintain long-term and efficient operation of AET systems [13]. 


\subsection{Australia}

Australia's early toll roads were developed and operated by the government, but private investment increased in the early 1990s. Currently, 16 toll roads are operated and Australia's toll system adopts various types of systems such as fixed rate, distance rate and time rate system. The tolls can be paid via E-tag and NSW Pass and New South Wales State introduced AET in 2013 [13].

\subsection{Norway}

In Norway, collects tolls on a project basis, tolls will be used for the construction of transportation infrastructure such as bridges and tunnels. Depending on with or without OBU(On-Board Unit) collect tolls types are divided into Auto Pass or video recognition. The AET was introduced in 2007, and the utilization rate as of 2015 reached $90 \%$ [13].

\subsection{Canada}

In Ontario, most of highways are free, but some roads and bridges are collect charges. The concept of congestion charge has been adopted to differentiate tolls. Like Norway the tolls can be collected with OBU or video recognition. The utilization rate is $84 \%$ [13].

\subsection{Taiwan}

Taiwan operates only some of the highways as toll roads, and adopting a distance-based rate system. Especially care for short-distance users for free up to $20 \mathrm{~km}$ per day. The AET was introduced in 2012, but when utilization was low, the eTag were distributed for free. Consequently raising the utilization to $94 \%$ [13].

\section{Simulation}

\subsection{Traffic Flow Model}

This study examines the effects of applying a smart tolling system to current tollgates to improve traffic flow. The Korea Expressway Corporation's actual traffic data (Mon-day, 3/7/2016) were used for analysis, and a model of the entry section of the Seoul tollgate on the Gyeongbu highway was developed using ARENA 14.0. According to the data, the section was divided into 20 booths in 5 lanes, as shown in Table 2 .

Table 2: Seoul Tollgate Entry Section

\begin{tabular}{lll}
\hline Number of Lanes & Number of Booths & Type of Lane \\
\hline 1 & $1-4$ & Hi-pass \\
2 & $5-9$ & Regular \\
3 & $10-14$ & Regular \\
4 & $15-17$ & Hi-pass \\
\hline
\end{tabular}




\begin{tabular}{lll}
\hline 5 & $18-20$ & Regular \\
\hline
\end{tabular}

The arrival distribution time was estimated by the traffic volume between 8 a.m. and 10 a.m. (the peak time during rush hour) using an input analyzer included in ARENA 14.0. The results are listed in Table 3. Some booths were unable to estimate the distribution time as they were operated differently according to the tollgate situation.

Table 3 : Arrival Distribution Time for Each Booth

\begin{tabular}{ll}
\hline Number of Booths & Arrival Distribution Time \\
\hline 1 & $0.5+\operatorname{LOGN}(7.3,8.34)$ \\
2 & $0.5+\operatorname{LOGN}(2.71,2.39)$ \\
3 & $0.5+\operatorname{GAMM}(2.75,1.64)$ \\
4 & $0.5+\operatorname{LOGN}(4.79,5.33)$ \\
5 & - \\
6 & - \\
7 & $5+\operatorname{LOGN}(17.5,17)$ \\
8 & $9+\operatorname{LOGN}(16.5,21.8)$ \\
9 & $4.5+\operatorname{LOGN}(19.5,14.4)$ \\
10 & - \\
11 & $4+\operatorname{GAMM}(10.2,2.13)$ \\
12 & $7.5+\operatorname{LOGN}(16.6,17.3)$ \\
13 & $5+\operatorname{LOGN}(30.4,41.8)$ \\
14 & - \\
15 & $0.5+\operatorname{LOGN}(6.72,7.99)$ \\
16 & $0.5+\operatorname{LOGN}(8.51,11.5)$ \\
17 & $0.5+\operatorname{GAMM}(7.13,1.25)$ \\
18 & $8+167 * \operatorname{BETA}(0.807,4.95)$ \\
19 & - \\
20 & $7+\operatorname{LOGN}(46.6,110)$ \\
\hline
\end{tabular}

Entry roads were divided as shown Fig. 1. The number of zones and the lengths of zones are summarized in Table 4. Also the number of zones refers to the number of vehicles that can occupy the zone. 
Journal of Advanced Simulation in Science and Engineering

Table 4 : Number of Zones and Length of Zone by Section

\begin{tabular}{llll}
\hline Section & Number of Zones & Length of Zone & Length of Section $(\mathrm{m})$ \\
\hline Tollgate & 6 & 3 & 18 \\
1 & 20 & 4 & 80 \\
2 & 20 & 4 & 80 \\
3 & 13 & 4 & 52 \\
4 & 13 & 4 & 52 \\
5 & 8 & 4 & 32 \\
6 & 13 & 4 & 52 \\
\hline
\end{tabular}

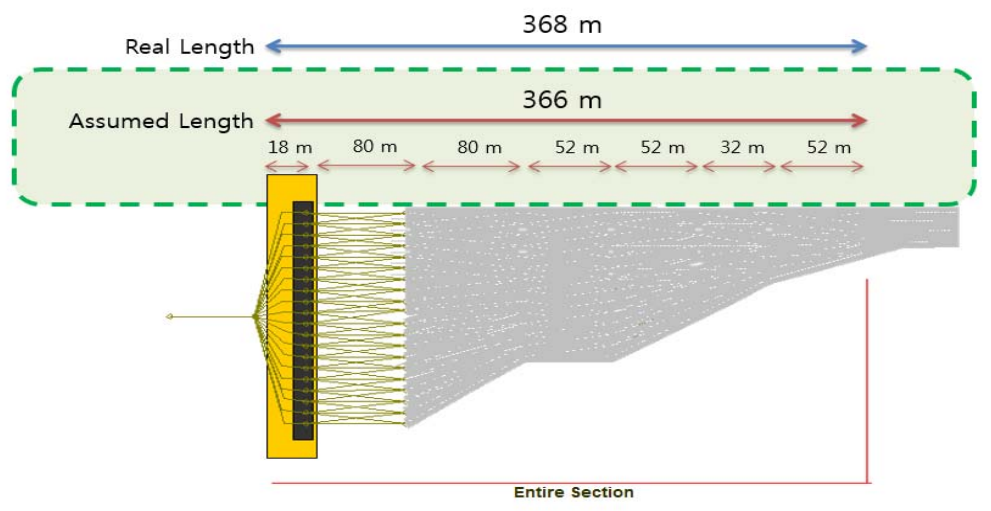

Figure 1 : Split-Entry Road Section

Several assumptions are described for the implementation and examination of simulation models at a possible level.

First, each vehicle moves in the direction of the lowest occupancy rate of any route that can be moved forward.

Second, the basic speed of all vehicles is set as the average speed of passing through the tollgate, which can only be identified by the data. However, if the passing interval time of two vehicles was $0 \mathrm{~s}$, it was converted to $1 \mathrm{~s}$.

Third, there is no classification between buses and vehicles, and so on.

Fourth, when moving diagonally to change lanes, the speed of the vehicle is re-duced slightly to the $90 \%$ level.

Fifth, when passing through a tollgate, the speed of vehicles in regular lanes is ad-justed to the $20 \%$ level, assuming the speed at which it stops and starts for payment.

Sixth, the length of the zone was set to $4 \mathrm{~m}$, and the length of the vehicle was set to $3 \mathrm{~m}$.

Seventh, when the vehicle starts to move to the next zone, the current zone is re-leased.

Eight, the actual total length was $368 \mathrm{~m}$, but in the model, the length was set to $366 \mathrm{~m}$ to divide by zone.

Nine, as basic research, the acceleration and deceleration of each vehicle were not considered. 


\section{Journal of Advanced Simulation in Science and Engineering}

\subsection{Simulation Model 1 with Hi-pass and Regular Lanes}

To simulate traffic flows such as the current situation, the model was implemented using networks and zones. The model was implemented as a section between toll-gates with 20 lanes merging into 5 lanes, as shown in Fig. 2.

Traffic Flow at a Seoul Tollgate with Hi-pass and Regular Lanes
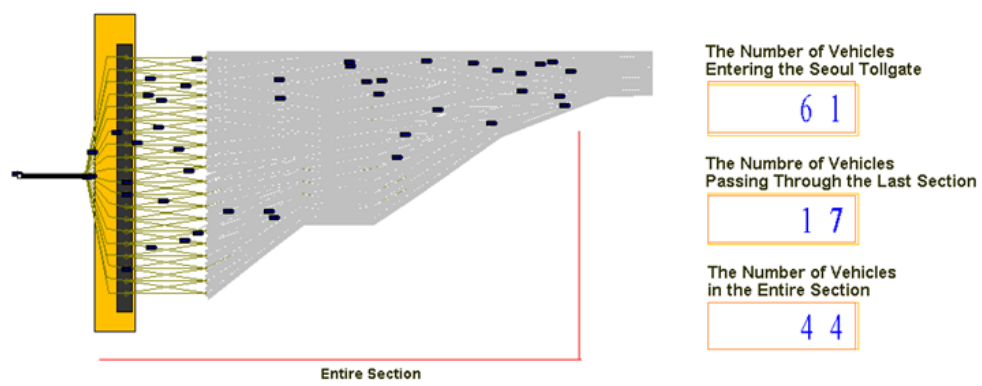

Figure 2 : Hi-pass and Regular Lane Model

The speeds of the Hi-pass vehicles were estimated by real data using the input analyzer program included in the ARENA software, and the results are shown in Fig. 3.

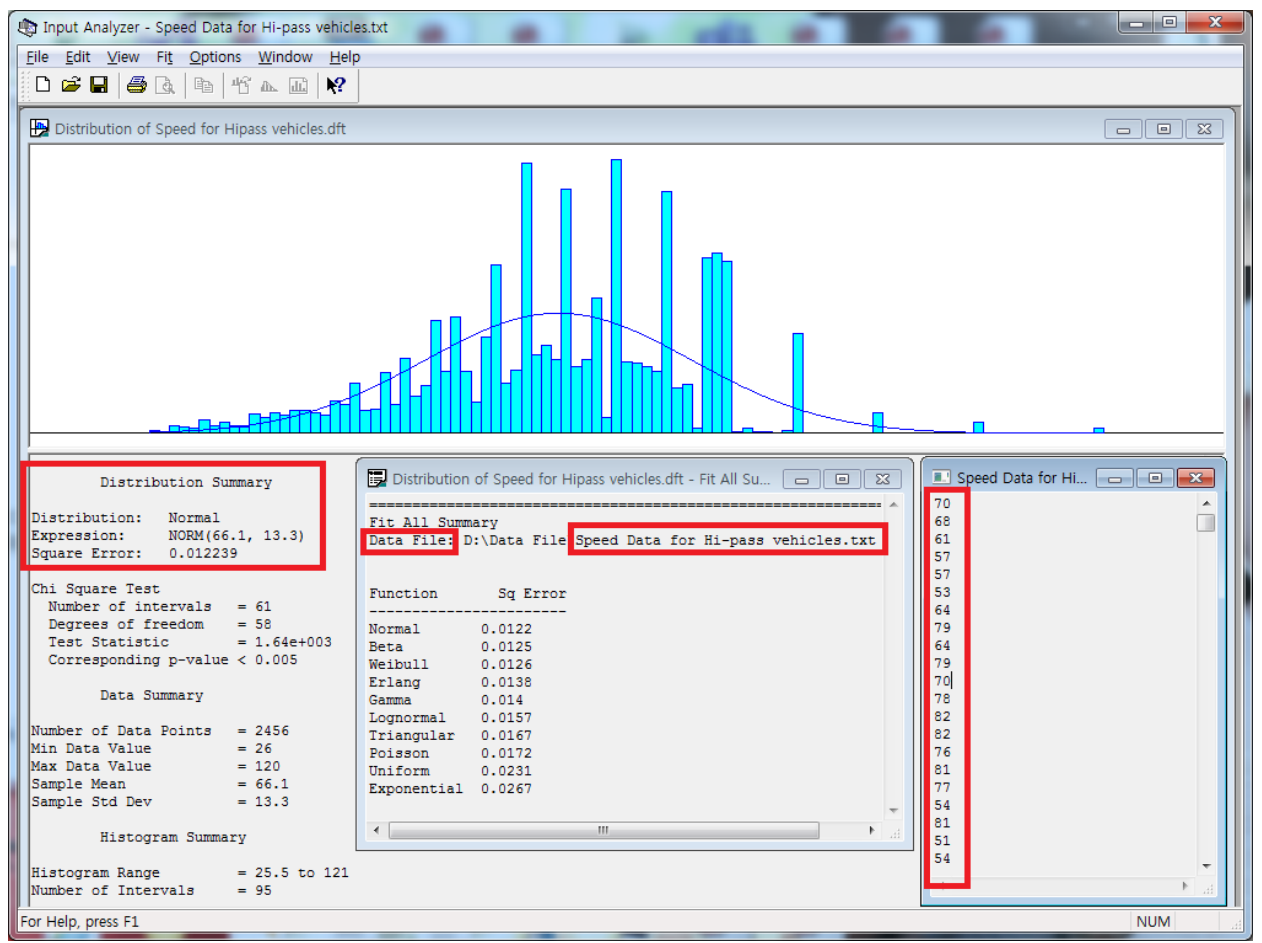

Figure 3 : Distribution of Speeds for Hi-pass vehicles

The time to pass through the tollgate section was separated by lane type. For vehicles in Hi- 
Journal of Advanced Simulation in Science and Engineering

pass lanes, the transit time was calculated by dividing the distance of the tollgate section (18 m) by the speed $(\mathrm{m} / \mathrm{s})$ of each vehicle. For vehicles in regular lanes, the payment time was calculated as the sum of the average response time (1.25 s) and average service time (11.65 s). This was done by referring to the Korea Highway Corporation's service report [14] and adjusting the speed of passing through the tollgate to $20 \%$. Table 5 lists the adjusted speeds and transit (payment) times by lane type.

Table 5 : Adjusted Speed and Transit (Payment) Time by Lane Type

\begin{tabular}{lll}
\hline Type of Lane & Adjustment of Tollgate Section Speed (\%) & Transit (Payment) Time(s) \\
\hline Hi-pass & 100 & $\frac{18 \mathrm{~m}}{\left(\text { vehicle speed } \times \frac{1000 \mathrm{~m}}{3600 \mathrm{~s}}\right)}$ \\
Regular & 20 & 12.9 \\
\hline
\end{tabular}

\subsection{Simulation Model 2 with Smart Tolling}

The basic model was implemented to simulate the traffic flow for smart tolling as defined by the Ministry of Land, Infrastructure and Transport using networks and zones as in model 1. Model 1 merges into 5 lanes from 20 lanes, but model 2 main-tains 5 lanes without a tollgate. Model 2 was implemented for the same section of model 1 in order to compare the two, as shown in Fig. 4.

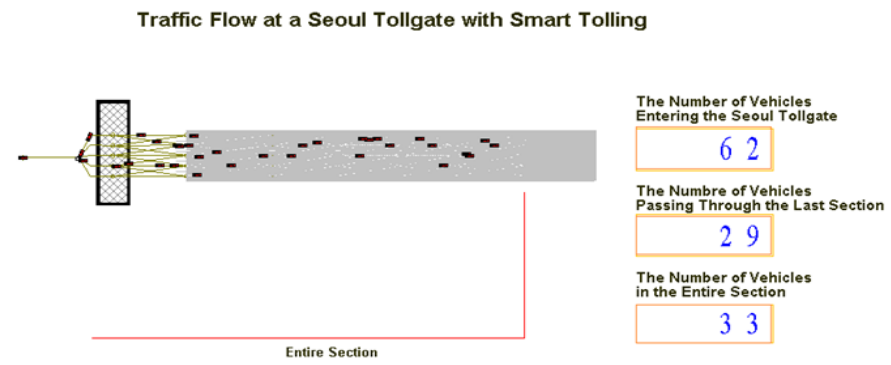

Figure 4 : Smart Tolling Model

The speed of the vehicle is same as in model 1 , and there is no transit time caused by the lack of a tollgate.

\subsection{Scenario Design}

The scenarios were divided by vehicle speed. Because the current speed uses distribu-tion values, some vehicles drive very slowly at a low probability. This may result in a time loss for subsequent vehicles. Table 6 lists the scenarios. 
Table 6 : Scenarios

\begin{tabular}{lll}
\hline Scenario & Model & Vehicle Speed $(\mathrm{km} / \mathrm{h})$ \\
\hline 1 & Model 1 & $\operatorname{NORM}(66.1,13.3)$ \\
2 & Model 1 & 60 \\
3 & Model 1 & 100 \\
4 & Model 1 & 110 \\
5 & Model 2 & $\operatorname{NORM}(66.1,13.3)$ \\
6 & Model 2 & 60 \\
7 & Model 2 & 100 \\
8 & Model 2 & 110 \\
\hline
\end{tabular}

\section{Simulation Results and Analysis}

\subsection{Evaluation Criteria}

In this study, the levels of improved traffic flow were compared by applying a basic model of smart tolling at the Seoul tollgate during peak hours. To compare the results of the two models, three criteria of evaluation were set.

First, the average number of vehicles in the entire section represented the level of congestion. If the number is high, then it means the traffic is not flowing smoothly.

Second, the throughput value representing the level of traffic handling is calculated by the number of vehicles passing through the last section divided by number of vehicles entering the tollgate.

Third, the average duration time was set as a secondary measure. If the time is long, then it means the traffic flow is poor.

\subsection{Validation of the Number of Replications}

When comparing simulation results, reliability of the experimental results must be ensured. A sufficient replication number of experiments is needed. If the results have a large error, then the experiment cannot be reliable. Experimental results with 30 replications for the error rate of the evaluation criteria using the half width of a $95 \%$ confidence level interval provided by ARENA are listed in Table 7.

Table 7 : Error Rates of Evaluation Criteria by Scenario with 30 Replications

\begin{tabular}{llll}
\hline Scenario & Level of Congestion (\%) & Throughput (\%) & Duration (\%) \\
\hline 1 & 0.43 & 0.02 & 0.15 \\
2 & 0.33 & 0.02 & 0.14 \\
3 & 0.34 & 0.01 & 0.11 \\
4 & 0.32 & 0.01 & 0.12 \\
\hline
\end{tabular}




\begin{tabular}{llll}
\hline \hline 5 & 0.34 & 0.02 & 0.09 \\
6 & 0.27 & 0.02 & 0 \\
7 & 0.3 & 0.01 & 0 \\
8 & 0.27 & 0.01 & 0 \\
\hline
\end{tabular}

It was confirmed that there were no problems using these values because all error rates were lower than $0.5 \%$.

\subsection{Experiment Results}

Table 8 lists the values of the experiment criteria by scenario.

Table 8 : Values of Evaluation Criteria by Scenario

(Unit: Number of Vehicles, \%, s)

\begin{tabular}{llll}
\hline Scenario & Level of Congestion & Throughput & Duration \\
\hline 1 & 39.9787 & 99.62 & 27.3022 \\
2 & 41.8726 & 99.59 & 28.5477 \\
3 & 26.7366 & 99.74 & 18.2479 \\
4 & 24.7097 & 99.77 & 16.8265 \\
5 & 32.7607 & 99.68 & 22.3330 \\
6 & 33.9423 & 99.68 & 23.1064 \\
7 & 20.2515 & 99.80 & 13.7774 \\
8 & 18.3895 & 99.82 & 12.5095 \\
\hline
\end{tabular}

The results of level of congestion show that if the vehicle speed is low, then the number of vehicles in the entire section is higher. In the most congested situation of scenario 2 , an average of 41.8726 vehicles remained in the experimental period, while 18.3895 vehicles remained in scenario 8 .

The throughputs of scenarios 4 and 8 were the highest by model. The transit times were short because each vehicle drove at a speed of $110 \mathrm{~km} / \mathrm{h}$. The throughputs were $99.77 \%$ and $99.82 \%$, respectively. The throughput of scenarios 2 and 6 were the lowest by model. The speed was 60 $\mathrm{km} / \mathrm{h}$, and the throughputs were $99.59 \%$ and $99.68 \%$, respectively. As a result, the current number of vehicles can be handled even if the number of lanes is shrunk to five by applying model 2.

For the average duration time, scenarios 2 and 6 by model were the longest at $28.5477 \mathrm{~s}$ and $23.1064 \mathrm{~s}$, respectively. Scenarios 4 and 8 by model had the shortest times at $16.8265 \mathrm{~s}$ and $12.5095 \mathrm{~s}$, respectively. 


\section{Journal of Advanced Simulation in Science and Engineering}

Most tollgates have Hi-pass and regular lanes together. In reality, this is similar to the situation in scenario 1 . The smart tolling model will be similar to the situation in scenario 8 using a $110 \mathrm{~km} / \mathrm{h}$ highway speed limit. These are the key results when scenario 8 is applied to the situation in scenario 1 .

First, the level of congestion will drop from 39.9787 vehicles to 18.3895 vehicles for a percentage of about $46 \%$.

Second, the throughput will increase slightly, from $99.62 \%$ to $99.82 \%$.

Third, the average duration time will drop from $27.3022 \mathrm{~s}$ to $12.5095 \mathrm{~s}$ for a per-centage of about $45.8 \%$.

Consequently, the level of congestion and the average duration time are expected to have significant positive effects.

\section{Conclusion}

In this study, the effects of applying the basic model of a smart tolling system that is currently under active discussion were compared. To compare the results, a simulation was conducted on vehicles entering a Seoul tollgate that is large and often congested.

The results of the experiments with the smart tolling model showed that the level of congestion and average duration time significantly decreased by about $46 \%$. The effects of improvements in the traffic flow were seen to be sufficient even though the number of lanes remained at five. Of course, the duration decreases in part by the given payment time. Extensions of the lane seem unnecessary because the throughputs are similar between models.

Results of the case study, since already considering video recognition and OBU in Korea, there seems to be no problem in collecting tolls, but the issue of personal information due to images from video recognition must be dealt at the government level.

According to the Korea Expressway Corporation's notice, the Hi-pass utilization rate was $79.8 \%$ as of December 2017 [15], so there will be no problems even if Smart Tolling is applied.

The limitations of this study as follows: The models were implemented at a fundamental level but tried to reflect reality through assumptions. Settings such as acceleration or deceleration were not implemented. In addition, data should be updated through the information disclosure claim.

Based on this model, a new model will be implemented for additional settings such as extensions of sections, vehicle separation, acceleration, and deceleration, and so on. By changing to smart tolling, this research will be expanded to include an economic analysis of unused land.

\section{Acknowledgement}

This study was supported by the Research Program funded by the Seoul National University of Science and Technology.

\section{References}

[1] Ministry

of Land,

Infrastructure

and

Transport: 
Journal of Advanced Simulation in Science and Engineering

http://www.molit.go.kr/USR/NEWS/m 71/dtl.jsp?id=95081827

[2] Korea Expressway Corporation: http://www.ex.co.kr/portal/biz/bbs/layout1/selectBoardArticle.do?bbsId=BBSMSTR 000000000183\&nttId=11723

[3] Lee, U.J., Kim, S.T., Kim, C.K., Park, J.H., Park, G.H.: The Smart Tolling Which Next generation payment system with multiple lane and non-stop. Journal of the Korean Society of Road Engineers, 16:1 (2014), 46-50.

[4] Ministry of Land, Infrastructure and Transport: http://www.molit.go.kr/USR/NEWS/m 71/dtl.jsp?id=95078761

[5] Korean National Police Agency: https://www.police.go.kr/por$\underline{\mathrm{tal} / \mathrm{bbs} / \mathrm{view} \cdot \mathrm{do} ? \mathrm{bbsId}=\mathrm{B} 0000032 \& \mathrm{nttId}=9676 \& \text { menuNo }=200629}$

[6] Lee, J.S., Lee, K.Y., Lee, C.K., Yun, I.S., Yu, J.W.: Estimation of Hi-pass Traffic Dispersion Rates to Determine the Optimal Location of Hi-pass Lanes at A Toll Plaza, Journal of The Korea Institute of Intelligent Transport Systems, 12:4 (2013), 22-32.

[7] Shin, H.S.: Operation decision model development and optimal operation of highway tollgate, Ph.D. Dissertation. Gachon University (2005).

[8] Yoo, B.S., Lee, S.B., Park, W.Y., Do, H.G.: Safety Improvement of Centrally Installed Hi-pass Lane of Express Highway, Journal of the Korean society of civil engineers, 30:1 (2010), 1-10.

[9] Yun, I.S., Han, E., Lee, C.K., Rho, J.H., Lee, S.J., Kim, S.B.: Mobility and Safety Evaluation Methodology for the Lo-cations of Hi-PASS Lanes Using a Microscopic Traffic Simulation Tool, Journal of the Korea Institute of Intelligent Transport Systems, 12:1 (2013), 98-108.

[10] Yoon, H.S.: Analysis of Construction Cost Savings of New Expressway with Smart Tolling Application, Master's thesis, Ajou University (2016).

[11] Delaware River Joint Toll Bridge Commission: http://www.scudderfallsbridge.com/faq/why-use-all-electronic-tolling-aet

[12] Hong, J.Y.: "U.S. ETCS Policy Trends : All Electronic Tolling” in Road Policy Brief No. 69 (Road Policy Center), Korea Research Institute for Human Settlements, Sejong, 2013, 4-5.

[13] Yeon, B.M.: "AET Cases and Implications for Smart Tolling" in Road Policy Brief No. 120 (Road Policy Center), Korea Research Institute for Human Settlements, Sejong, 2017, 8-9.

[14] Korea Highway Corporation: Master Plan for Hi-Pass and Hi-Pass Lane Selection Using a Simulation Tool, 2005.

[15] Korea Expressway Corporation: http://www.ex.co.kr/site/com/pageProcess.do?selDpPgNm=menuno $\% 3 \mathrm{D} 100505039 \& \operatorname{dirNm}=$ portal 